\title{
Study the impact of A nanomixture of carbon black and clay on the mechanical properties of A series of irradiated natural rubber/ butyl rubber blend
}

Dalal Alshangiti ( D Dalal.Alshangiti@gmail.com )

Imam Abdulrahman Bin Faisal University

Original Article

Keywords: Rubber, Nanocomposites, Radiation, mechanical properties, Theoretical modeling

Posted Date: April 7th, 2021

DOI: https://doi.org/10.21203/rs.3.rs-314648/v1

License: (c) (1) This work is licensed under a Creative Commons Attribution 4.0 International License.

Read Full License

Version of Record: A version of this preprint was published at e-Polymers on January 1st, 2021. See the published version at https://doi.org/10.1515/epoly-2021-0051. 


\title{
Study the impact of A nanomixture of carbon black and clay on the mechanical properties of A series of irradiated natural rubber/ butyl rubber blend D M Alshangiti
}

Department of Physics, College of Science and Humanities- Jubail, Imam Abdulrahman Bin Faisal University, Jubail, KSA

\begin{abstract}
:
A series of natural rubber/ butyl rubber NR/IIR blend loaded with N660 carbon black CB and triethoxy vinyl silane treated clay nano particles (TCNP) were prepared using gamma irradiation in the presence of polyfunctional monomer, trimethylolpropane triacrylate (TMPTA). The effect of incorporating different content of N660 carbon black and 5 part per hundred of rubber (phr) of treated clay on the mechanical properties of the prepared nano composites have been investigated. The additions of TCNP into $\mathrm{CB} /$ rubber composites markedly increase their tensile strength due to the increase of the cross-link density. These results indicated that the TCNP may be enclosed or trapped in the occluded structure of CB. The effect of CB and TCNP content on the tensile strength $(\sigma)$, elongation at break $(\varepsilon \mathrm{b} \%)$ and modulus of elasticity $(E, \mathrm{MPa})$ of natural rubber/ butyl rubber NR/IIR blend have been investigated. The incorporation of $5 \mathrm{phr}$ of TCNP into $30 \mathrm{phr}$ carbon black loaded NR/ IIR composites results in the increased tensile strength value by about $60 \%$. Finally, theoretical models were used to interpret the experimental results.
\end{abstract}

Keywords: Rubber; Nanocomposites; Radiation; mechanical properties; Theoretical modeling.

Corresponding Author: Dalal M Alshangiti, College of Science and Humanities- Jubail, Imam Abdulrahman Bin Faisal University, P.O.Box 12020, Jubail, KSA. E mail: dalshangite@iau.edu.sa; Dalal.Alshangiti@gmail.com Tel:+966507759347. 


\section{Introduction}

Blending of polymers provides an attractive way for producing new materials have peerless combinations of properties not available in a mono polymer. Co-continuous polymer blends may have number of beneficial properties that make it possible to be used in various potential applications [1]. Some of the beneficial properties of co-continuous polymeric blends include: controlled electrical conductivity, synergistic mechanical properties, or selective permeability [24]. One of the methods to enhance the mechanical properties of polymeric materials is the incorporation of structure particulate fillers like carbon black, graphite, silica etc. Carbon black (CB) reinforced filler is most often used. Composites containing conductive CB dispersed in various polymeric matrixes have been developed and their properties studied extensively [5-7]. One of the most ultimate properties of polymeric materials is the possibility of developing their physicomechanical properties by means of manipulation designed specifically of their nanoscopic structures. Where organic and inorganic substances can be combined formatting a nano-scaled matrices and can show improved hardness, strength, stiffness and thermal stability, which is individual and differ than any other current compounds with typical filler loading less than $5 \mathrm{wt} \%$ [8]. Since the inorganic fillers have strong reinforcement ability concerning to their particle aspect ratio, frequently used particulates inorganic filler are bentonite and clay mineral.

When nominate a particular formularization for physicomechanical or engineering applications, it is very important to distinguish the precept factors concerned in stability and degradation in material planning issues. For example, irradiation of polymers causes permanent structural modifications such as crosslinking, end linking and chain scission as well as the engenderment of volatile degradation products which affects the molecular weight distribution [9]. Recently the use of radiation technology in polymer processing received a great deal of interest for numerous reasons, including radiation induced crosslink of cross-linking type polymers, low cost of curing or processing, and the green technologies. It is recognized that the exposure of these type polymers to ionizing radiation such as gamma rays and accelerated electrons provides incremented stability and ameliorated physicomechanical properties [1-5]10]. Polyolefins, such as natural rubber (NR) and butyle rubber (IIR) elastomers are capable of forming intermolecular junctions when subjected to ionizing radiation either in pristine or compounded state [11]. These types of materials (Polyolefins) have a range of features that make it widely applied in industrial applications. For example IIR has remarkable gas resistance and 
moisture (water and steam) permeation. It also has superior resistance to alkalis, certain solvents such as ketones and alcohols, abrasion and flexing. While NR is widely used where low or normal (not high) oxidizing types of bases and acids are present.

In this paper, polyfunctional monomers, trimethylolpropane triacrylate (TMPTA), was chosen to sensitize radiation vulcanization of NR/ IIR rubber blends. The effect of triethoxy vinyl silane (TEVS) treated clay nano particles on the mechanical properties of 50/50 NR/ IIR blend have been investigated. Due to our familiarity, no investigations or reports were investigated on the effect of treated nano clay on the mechanical properties of NR/IIR blend loaded with N660 CB that cured by ionizing radiation.

\section{Experimental}

\subsection{Materials}

Natural rubber (NR), Butyl Rubber (IIR) and general purpose furnace (GPF, N660) carbon black (CB) were supplied by Transport and Engineering Co. (TRENCO), Egypt. Highly fined clay (bentonite, BE125) was supplied by Spectrum Chemicals\& Laboratory Products, USA. Radiation coagent namely trimethylolpropane triacrylate (TMPTA, multifunctional monomer, density $=0.936$ ) was supplied by Alnasr chemicals Co., Egypt. TMPTA was used as multifunctional low molecular weight radiation sensitizer and used without further purification. Triethoxy vinyl silane (silane coupling agent, TEVS) (b.p. $160-161^{\circ} \mathrm{C}$ ) is obtained from Aldrich Chemical Company Inc., Germany. The basic characteristics of bentonite and N660 are given in Table 1.

\subsection{Modification of clay}

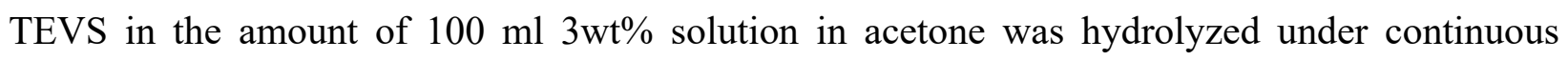
stirring for 1 hour. Then, the silylation reaction was carried out by pouring the hydrolyzed TEVS into the clay dispersion under vigorous stirring for 24 hours at room temperature. The organoclay were then left in a vacuum oven at $110{ }^{\circ} \mathrm{C}$ for $24 \mathrm{hrs}$. The dry fillers were then ground into fine powders.

\subsection{Compounding and irradiation of the samples}

Rubber blends (blend ratio 50/50 $\mathrm{wt} \%$ ) of $\mathrm{NR}$ and IIR were blended using Brabender Plasticorder (Model PLE-330, mixing chamber Model W50-EHT, chamber volume $50 \mathrm{~cm}^{3}$, mixing temperature $70^{\circ} \mathrm{C}$, mixing speed $40 \mathrm{rpm}$ ) for a period of $7 \mathrm{~min}$. Afterward, $\mathrm{CB}$ was added and mixed for $3 \mathrm{~min}$, then the treated clay was added into the rubber and was mixed for 3 min 
and finally the TMPTA was added and mixed for $2 \mathrm{~min}$. The sample designations are tabulated in Table (2). The gradient is presented in parts per hundred parts from rubber by weight (phr). The obtained compound master batch (final mixing) then passed through a two roll mill three times. The sheets were compression moulded at $5 \mathrm{MPa}$ pressure and $110^{\circ} \mathrm{C}$ and in an electrically heated press for $3 \mathrm{~min}$ to obtain uniform sheets of thickness $\approx 2 \mathrm{~mm}$. The moulded samples, in the form of thin sheets, have been irradiated at $50 \mathrm{kGy}$ dose [12] by ${ }^{60} \mathrm{Co} \gamma$-irradiation at a dose rate $7.75 \mathrm{kGy} / \mathrm{h}$ at $40^{\circ} \mathrm{C}$. The ${ }^{60} \mathrm{Co} \gamma$-source model GB150 type B manufactured by the AEA of Canada and located at National center for Radiation Research and Technology, Cairo, Egypt.

\subsection{Mechanical properties measurements}

The stress-strain measurements of the filled irradiated NR/ IIR composites was measured using tensile testing machine, type $\mathrm{H} 10 \mathrm{KS}$, at $5 \mathrm{~mm} /$ minute displacement speed. Three samples per formulation were tested. The tensile machine automatically gives values of tensile strength, elongation \% and young's modulus

\section{Results and Discussion}

The stress-strain measurements is the most important tool that can be clarified Characteristics of elastomers. The elastic energy stored in an elastomer as a result of distortion or deformation under the influence of an applied stress is of great interest for scientists.

\subsection{Effect of carbon black loading on the mechanical properties}

The stress- strain characteristics of radiation cross-linked NR/IIR blend are illustrated in Fig. 1,

as a function of GPF CB content. The tensile strength $(\sigma)$, elongation at break $(\varepsilon \mathrm{b} \%)$ and modulus of elasticity (E, MPa) obtained from Fig. 1 are presented in Table (3). The modulus of elasticity was obtained from first few points of each curve. $E$ and $\sigma$ of NR/IIR blend increased with increasing GPF content due to strong polymer chains/ CB filler interactions, and/or between filler and filler. In fact, the molecular mobility decreases with increase in reinforcing filler loading, leads to formation of physical bonds between incorporated fillers and the polymer chains. On the other hand, the presence of filler particles decreases the elongation at break gradually, as expected, because it restricts the macromolecular chain elongation of rubber matrix [13].

\subsection{Effect of nanoclay on the mechanical properties}

The effect of TCNP loading on the mechanical properties of rubber- CB composites was investigated using montmorillonite, which was mixed with the GPF filled at $5 \mathrm{phr}$ loading. The 
stress-strain curves are shown in Fig. 2, which elucidate the reinforcing effect of the nanoclay. The mechanical parameters obtained from Fig. 2 are presented in Table (3). A pronounced increase in tensile strength and modulus in clay filled $\mathrm{CB} /$ rubber composites with respect to the samples containing similar dose of carbon black were detected. The ratio of $\sigma$ value of the TCNP loaded composites with respect to that of the $\mathrm{CB} /$ composite is always higher than one. On the other hand, the modulus increases and the elongation at break decreases with incorporating clay nano filler. The incorporation of $5 \mathrm{phr}$ of montmorillonite clay enhances the modulus by 15,1 , 40 and $80 \%$ and tensile strength by 17, 32, 60 and $53 \%$ for the 10, 20, 30 and $50 \mathrm{phr}$ CB loaded rubber, respectively. As a conclusion, the addition of $5 \mathrm{phr}$ of TCNP to $30 \mathrm{phr}$ N660 CB filled NR/IIR (50/50 wt \%) sample increased its tensile strength value by about $60 \%$.

\subsection{Effect of nature of fillers on the single phase rubber}

According to the good reinforcement that has been obtained as a result of incorporating $30 \mathrm{phr}$ of $\mathrm{CB}$ and $5 \mathrm{phr}$ of treated clay, it is interesting to study the effect of these concentrations on the mechanical properties of both NR and IIR. The stress-strain graphs of $30 \mathrm{phr}$ GPF and $30 \mathrm{phr}$ GPF and $5 \mathrm{phr}$ of treated clay filled NR and are shown in Figures 3. The values of $\varepsilon_{b} \%, \sigma(\mathrm{MPa})$ and $E(\mathrm{MPa})$ are reported in Table (3). Addition of $5 \mathrm{phr}$ of TEVS modified nanoclay into $30 \mathrm{phr}$ $\mathrm{CB}$ filled NR increases tensile strength from $21.4 \mathrm{MPa}$ to $31.9 \mathrm{MPa}$ (49\% increment) and modulus from $0.11 \mathrm{MPa}$ to $0.37 \mathrm{MPa}$ (236\% increment). The elongation at break decreases from $214 \%$ to $113 \%$ with the addition of modified nanoclay. On the other hand the addition of $5 \mathrm{phr}$ of treated clay into $30 \mathrm{phr}$ N660 filled IIR improves the tensile strength from 14.5 MPa to 17.2 MPa (18\% increase) and modulus from $0.095 \mathrm{MPa}$ to $0.178 \mathrm{MPa}$ ( $87 \%$ increase). While the elongation at break decreases from $188 \%$ to $117 \%$. These results indicating that the long chain silane modifiers facilitate the rubber chains to intercalate. The organoclay interact well with both polar NR and non pola IIR. It is well known that the mechanical properties depending mainly on polymer- filler and filler-filler interactions [14].

\subsection{Crosslinking density $(\eta)$}

Physical qualification of cross-linked nano composites can be characterized by determining its volume average cross-link density. The average cross-link density $(\eta)$ of elastic materials can be determined from mechanical or swelling Investigations. The cross-linking density values of the IIR, NR and their blends loaded with different fillers have been calculated by using the relation [15] 


$$
\eta=\frac{F}{2 A_{0} \rho_{p} R T\left(\lambda-\frac{1}{\lambda^{2}}\right)}
$$

Where $\sigma=F / A 0, \lambda(=\varepsilon+1)$ is the extension ratio, $\rho_{p}$ is the density of the tested sample, $R$ is the universal gas constant, $\mathrm{A}_{0}$ is sample cross sectional area and $T$ is the absolute temperature. The cross-linking density values are calculated and presented in Table (3). The cross-link density of NR/IIR blend increased with increasing GPF content due to strong polymer/ CB filler interactions (which is the main responsible factor in reinforcement mechanism). On the other hand, the cross-link density increases with adding $5 \mathrm{phr}$ of treated clay into the matrix. The incorporation of TCNP enhances the cross-link density with respect to the conventional CB loaded composites at different $\mathrm{CB}$ contents. The ratio of the cross-link density of the nanocomposite containing TCNP to that of the CB loaded composites is always higher than one. TCNP may be trapped in the occluded structure of carbon black, thus increases the coross-link density. Thus, both CB particles and TCNP contribute towards the higher cross-link density. Moreover, NR loaded with 30phr of black (N660) has a higher cross-link density compared with IIR sample loaded with similar content of CB. Also the incorporation of $5 \mathrm{phr}$ of treated clay enhances the cross-linking of both samples.

\subsection{Theoretical modeling}

\section{Young's modulus}

The mechanical properties of filler-rubber composites are influenced by various parameters such as filler type and concentration, filler orientation, filler-matrix interaction, filler-filler wettability and filler respect ratio. A number of theories and equations have been developed in the literature, to foretell the properties of the polymer composites. The optimum mechanical properties of the composite are strongly dependent on filler-matrix interactions [16, 17].

The mechanical behavior of composite materials was described by different theories in terms of various parameters. Einstein, Guth, Sato-Furukawa and Quemeda are the most famous theoretical models selected to describe the mechanical behavior of particulated filler- matrix systems [18, 19]. These models are mainly applied for the theoretical calculations of the physicomechanical properties of spherical shaped fillers reinforced polymer composites. Einstein's equation which mainly applied in the cases of entire adhesion and highly dispersed filler particles has the form [20] 


$$
E=E_{m}\left(1+2.5 V_{f}\right)
$$

where $E_{m}$ and $E$ are the Young's modulus of the non-filled and filled matrix, respectively, and $V_{f}$ is the filler volume fraction. This equation suggests that the reinforcing action or stiffness of filler is independent of the fillers particle size. The equation shows that the volume occupied by the filler is independent of the size of the filler particles, i.e. the volume occupied by the filler rather than its weight is the dominant variable. This model also postulates that the filler is much more rigid than the host material chains.

The originally developed equation of Einstein's theory, which explains rubber reinforcement, is due to Guth and Smallwood equation. This equation is suitable to describe the behavior of rigid spherical filler and has the form:

$$
E=E_{m}\left(1+2.5 V_{f}+14.1 V_{f}^{2}\right)
$$

This equation takes in consideration the antiparticle (filler- filler) interactions at higher filler concentrations [21].

For discontinuous blend polymer systems that incorporated with spherical, rigid articulated fillers exhibit some adhesion, the Quemeda equation (equation 4) [22] could be applied to evaluate $E$ value of the composition. The usual forms are:

$$
E=\frac{E_{m}}{\left(1-0.5 K V_{f}^{2}\right)}
$$

where $K$ is an adjustable coefficient is introduced to account for the filler-filler interactions and their aspect ratio. For composites filled with nano particles, ' $K$ ' is taken as 2.5 [18].

The theoretical prediction based on the data created with polymer composites loaded with spherical particles is Thomas equation

$$
E=E_{m}\left(1+2.5 V_{f}+10.05 V_{f}^{2}+0.00273 \exp \left(V_{f}\right)\right)
$$

The previous theoretical empirical relationships are correlated with the obtained data and graphically represented in Fig. 4 (a, b). Experimentally determined values of the corresponding modulus values versus $V_{f}$ for CB loaded NR/ IIR blends are represented in Fig. 4- a. It can be seen that the experimental results are well in agreement Thomas relation (equation (5)).

Fig. 4-b shows that, the experimental values of modulus for treated clay incorporated $\mathrm{CB} /$ rubber nanocomposites have significant positive deviations compared with the calculated theoretical values. 
All these predictions did not give a clear explanation for the reason to increase $E$ values for the compositions containing TCNP. These predictions assume that any interaction operative would only be physical. The enhancement of the modulus for compositions containing TCNP may not be attributed simply to the introduction of inorganic filler into the rubber matrix.

\section{Tensile strength}

The value of tensile strength of filled polymers is a characteristic that is complicated to predict as it depends on polymer type and filler interfacial bonding as well as the previous factors mentioned above. Tensile strength is the force required to exert a uni-axial extension of a sheet of material to the point where it breaks. Specifically, the tensile strength is the maximum magnitude of force stress that applied of a material until it breaks. Elastomeric materials, such as NR/ IIR blend, have a yield point, which means that strength at break and ultimate strength are not the same.

A simple model for the determination of tensile stresses for unfilled and filled polymer was suggested by Turcsanyi et al [23]

$$
\sigma=\frac{1-V_{f}}{1+A V_{f}} \sigma_{m} f\left(V_{f}\right)
$$

where $\sigma_{m}$ and $\sigma$ are the tensile strength of unfilled and filled polymers, respectively. This model describes the composition dependence of the tensile strength. The value of $A(=2.318)$ for facecentered cubic packing while $A(=2.318)$ for a hexagonal close packing [23]. After applying eq. (6) to a various polymer/filler systems, was best described by an exponential function. The resulting expression was [23]

$$
\sigma=\sigma_{m} \frac{1-V_{f}}{1+2.5 V_{f}} \exp \left(B V_{f}\right)
$$

where $B$ is a fitting parameter associated to the interfacial properties.

Moreover, extensive works have been reported by several researchers, including Nielsen [24], Piggot and Leidner [25], and Nicolais and Narkis (N-N model) [26]. All theories postulate the relationship between tensile strength and the filler volume fraction $\left(V_{f}\right)$. Nicolasis and Narkis suggested that the area fraction depends on the volume fraction to the two thirds power,

$$
\sigma=\sigma_{m}\left(1-K V_{f}^{2 / 3}\right)
$$


where, $K$, is a fitting parameter depends on the attractive adhesion between pristine matrix and the filler particles; the low value of $K$ means the better the adhesion. $\mathrm{K}$ value is found to be $\approx 1.2$ for the extreme case of weak adhesion [27].

Fig $5(\mathrm{a}, \mathrm{b})$ compared the models used for tensile strengths with the experimental values. The samples which loaded with different volume fraction of N660 CB are presented in Fig 5-a. while those loaded with treated clay are presented in Fig 5-b. the experimental results show considerable positive deviations. This clearly obviously shows the reinforcing ability of both CB and TCNP clay in NR/ IIR blend matrix.

\section{Conclusions}

In this work blends of natural rubber/ butyl rubber NR/ IIR 50/50 nanocomposites containing different doses of general purpose furnace GPF carbon black and TCNP were prepared by melt mixing process. Blend ratio of rubber phases (NR/IIR, 50/50 wt \%) and the amount of TCNP (5 phr) were kept constant. The samples were then crosslinked using gamma irradiation in the presence of radiation coagent, trimethylolpropane triacrylate (TMPTA). The mechanical properties of prepared composites have been discussed in terms of fillers type and concentration. The cross-link density of NR/IIR blend increased with increasing GPF content due to strong interactions between polymer chains and CB filler. The incorporation of $5 \mathrm{phr}$ of TCNP into carbon black loaded NR/ IIR composites results in the increased tensile strength and modulus of the nano-composite matrix. The addition of $5 \mathrm{phr}$ of TCNP to the sample containing $30 \mathrm{phr}$ of $\mathrm{CB}$ increased its tensile strength value by about $60 \%$. Finally, theoretical models were used to interpret the experimental results.

Availability of data and materials

The authors confirm that the data findings of this study are origin and is carried out at Department of Physics, College of Science and Humanities- Jubail, Imam Abdulrahman Bin Faisal University, Jubail, KSA

Competing interests

No Competing interests

Funding 
No Funding source

Authors' contributions

I carried the whole manuscript preparation and study and wrote the manuscript

\section{Acknowledgements}

I would like to thank our college in Department of Physics, College of Science and HumanitiesJubail, Imam Abdulrahman Bin Faisal University, Jubail, KSA 


\section{References:}

[1] Vijay, V.R., Anitha, A.M., Menon, A.R. R., 2016. Studies on blends of natural rubber and butadiene rubber containing silica- Organomodified kaolin hybrid filler systems. Polymer, $89: 135-142$

[2] Chen, J., Du, X.C., Zhang, W.B., Yang, J.H., Zhang, N., Huang, T., Wang, Y., 2013. Synergistic effect of carbon nanotubes and carbon black on electrical conductivity of PA6/ABS blend. Composites Science and Technology, 81: 1- 8.

[3] Xiang, F., Shi, Y., Li, X., Huang, T., Chen, C., Peng, Y., Wang, Y., 2012. Cocontinuous morphology of immiscible high density polyethylene/polyamide 6 blend induced by multiwalled carbon nanotubes network. European Polymer Journal, 48: 350-361.

[4] Li, L., Wang, Z., Zhao, P., Luo, Y., Liao, L., Xu, K., Li, P., Wang, Z., Peng, Z., 2017. Thermodynamics favoured preferential location of nanoparticles in co-continuous rubber blend toward improved electromagnetic properties. European Polymer Journal, 92: 275-286

[5] Spratte, T., Plagge, J., Wunde, M., Klüppel, M., 2017. Investigation of strain-induced crystallization of carbon black and silica filled natural rubber composites based on mechanical and temperature measurements. Polymer, 115: 12-20.

[6] Barrera, C.S., Cornish, K., 2016. High performance waste-derived filler/carbon black reinforced guayule natural rubber composites. Industrial Crops and Products, 86: 132-142

[7] Albert, K.J., Lewis, N.S., Schauer, C.L., Sotzing, G.A., Stitzel, S.E., Vaid, T.P., Walt, D.R., 2000. Cross-reactive chemical sensor arrays. Chemical Review, 100: 2595- 2626.

[8] Kim, G.M., Lee, D.H., Hoffmann, B., Kressler, J., StoÈppelmann. G., 2001. Influence of nanofillers on the deformation process in layered silicate/ polyamide-12 nanocomposites. Polymer, 42: 1095- 1100.

[9] Maxwell, R.S., Cohenour, R., Sung, W., Solyom, D., Patel. M., 2003. The effects of $\gamma$ radiation on the thermal, mechanical, and segmental dynamics of a silica filled, room temperature vulcanized polysiloxane rubber. Polymer Degradation and Stability, 80: 443450.

[10] Flores-Rojas, G.G., Bucio, E. 2016. Radiation-grafting of ethylene glycol dimethacrylate (EGDMA) and glycidyl methacrylate (GMA) onto silicone rubber. Radiation Physics and Chemistry, 127: 21-26. 
[11] Gillen, K.T., Clough, R.L., 1989. Time-temperature-dose rate superposition: A methodology for extrapolating accelerated radiation aging data to low dose rate conditions. Polymer Degradation and Stability, 24: 137- 168.

[12] Madani, M, Aly, R.A., 2010. Monitoring of the physical aging of radiation cross-linked conductive rubber blends containing clay nanofiller. Materials and Design, 31: 1444- 1449.

[13] Flandin, L., Hiltner, A., Baer, E., 2001. Interrelationships between electrical and mechanical properties of a carbon black-filled ethylene-octene elastomer. Polymer, 42: 827-838.

[14] Maiti, M., Sadhu, S., Bhowmick, A.K., 2005. Effect of carbon black on properties of rubber nanocomposites. Journal of Applied Polymer Science, 96: 443-451.

[15] Mark, H.F., Bikales, N.M., Overberge, C.G., Menges, G., 1986. Dielectric Heating to Embedding. Encyclopedia of Polymer Science and Engineering, 4, John Wiely and Sons, New York.

[16] Gahde, J., Muller, V., Lebedev, Y.V., Lipatov, Y.L., 1977. Effect of silane treatment of fillers in polyethylene-kaolin compositions. Polymer Science USSR, 19: 1446- 1452.

[17] Guth, J., 1945. Theory of Filler Reinforcement. Journal of Applied Physics, 16: 20- 24.

[18] Madani, M., 2010. Mechanical Properties of Polypropylene Filled with Electron Beam Modified Surface-Treated Titanium Dioxide Nanoparticles. Journal of Reinforced Plastics and Composites, 29: 1999- 2015.

[19] Selvin, T.P., Kuruvilla, J., Sabu, T., 2004. Mechanical properties of titanium dioxide-filled polystyrene microcomposites. Materials Letters, 58: 281- 289.

[20] Tavman, I. H., 1996. Thermal and Mechanical Properties of Aluminum Powder-filled Highdensity Polyethylene Composites. Journal of Applied Polymer Science, 62: 2161-2167.

[21] Maiti, S.N., Lopez, B.H., 1992. Interaction of polyamic acids and polyamic esters with copper and distributed polysilsesquioxane copolymers. Journal of applied polymer science, 44: 353-361.

[22] Abraham, R., Thomas, S.P., Kuryan, S., Issac, J., Nandakumar, K., Thomas, S., 2010. Structural and mechanical properties of YBCO-polystyrene composites. Journal of applied polymer science, 118: 1027-1041.

[23] Turcsanyi, B., Pukanszky, B., Tudos, F., 1988. Composition dependence of tensile yield stress in filled polymers. Journal of Materials Science Letters, 7: 160- 162. 
[24] Nielsen, L. E., 1966. Simple theory of stress-strain properties of filled polymers. Journal of applied polymer science, 10: 97-103.

[25] Piggot, M.R., Leidner, J., 1974. Misconceptions about filled polymers, Journal of Applied Polymer Science, 18: 1619-1623.

[26] Nicholas, L., Narkies, M., 1971. Stress-strain behavior of styrene-acrylonitrile/glass bead composites in the glassy region, Polymer Engineering and Science, 11: 194-199

[27] Bliznakov, E., White, C.C., Shawi, M.T., 2000. Mechanical properties of blends of HDPE and recycled urea-formaldehyde resin. Journal of Applied Polymer Science, 77: 3220-3227. 
Table (1): Bentonite and carbon black characteristics

\begin{tabular}{lll}
\hline Materials & Parameter & \\
\hline Carbon black GPF (N660) & mean particle size $(\mathrm{nm})$ & 62 \\
& pour density $(\mathrm{g} / \mathrm{cc})$ & 0.47 \\
& Iodine adsorption & 26 \\
& DBPa adsorption $(\mathrm{cc} / 100 \mathrm{~g})$ & 87 \\
& $\mathrm{~N}_{2}$ surface area $\left(\mathrm{m}^{2} / \mathrm{g}\right)$ & 27 \\
& Ash $(\%$ Max.) & 0.1 \\
\hline Bentonite (Montmorillonite) & mean particle size $(\mathrm{nm})$ & 100 \\
& Purity & $>98 \%$ \\
& Quartz content $(\mathrm{crystalline}$ silica) & $<2 \%$ \\
& pour density $(\mathrm{g} / \mathrm{cc})$ & $2.5-2.6$ \\
\hline
\end{tabular}

${ }^{a}$ Dibutyl Phthalate.

Table (2): Samples Designation and compounding.

\begin{tabular}{llllll}
\hline \multirow{2}{*}{ Designation } & \multicolumn{5}{c}{ Ingredient, phr } \\
\cline { 2 - 6 } & NR & IIR & clay & CB & TMPTA \\
\hline B0 & 50 & 50 & & & 4 \\
B10 & 50 & 50 & & 10 & 4 \\
B20 & 50 & 50 & & 20 & 4 \\
B30 & 50 & 50 & & 30 & 4 \\
B50 & 50 & 50 & & 50 & 4 \\
B10/5 & 50 & 50 & 5 & 10 & 4 \\
B20/5 & 50 & 50 & 5 & 20 & 4 \\
B30/5 & 50 & 50 & 5 & 30 & 4 \\
B50/5 & 50 & 50 & 5 & 50 & 4 \\
N30 & 100 & 0 & 0 & 30 & 4 \\
II30 & 0 & 100 & 0 & 30 & 4 \\
N30/5 & 100 & 0 & 5 & 30 & 4 \\
II30/5 & 0 & 100 & 5 & 30 & 4 \\
\hline
\end{tabular}


Table (3): Mechanical properties of un-filled and filled nanocomposites.

\begin{tabular}{lllll}
\hline sample & $E(\mathrm{M} \mathrm{Pa})$ & $\sigma(\mathrm{MPa})$ & $\varepsilon b(\%)$ & $\eta(\mathrm{mol} / \mathrm{kg})$ \\
\hline $\mathrm{B} 0$ & 0.047 & 1.5 & 68 & 797 \\
$\mathrm{~B} 10$ & 0.086 & 10.0 & 156 & 1300 \\
$\mathrm{~B} 20$ & 0.1 & 11.0 & 132 & 1729 \\
$\mathrm{~B} 30$ & 0.15 & 12.7 & 109 & 2303 \\
$\mathrm{~B} 50$ & 0.2 & 15.0 & 98 & 3100 \\
$\mathrm{~B} 10 / 5$ & 0.099 & 11.7 & 142 & 1565 \\
$\mathrm{~B} 20 / 5$ & 0.11 & 14.6 & 132 & 1824 \\
$\mathrm{~B} 30 / 5$ & 0.211 & 20.4 & 105 & 3399 \\
$\mathrm{~B} 50 / 5$ & 0.36 & 22.9 & 81 & 6104 \\
$\mathrm{~N} 30$ & 0.113 & 21.4 & 214 & 2224 \\
$\mathrm{II} 30$ & 0.095 & 14.5 & 188 & 1553 \\
$\mathrm{~N} 30 / 5$ & 0.375 & 31.9 & 113 & 6207 \\
$\mathrm{II} 30 / 5$ & 0.178 & 17.2 & 117 & 2907 \\
\hline
\end{tabular}




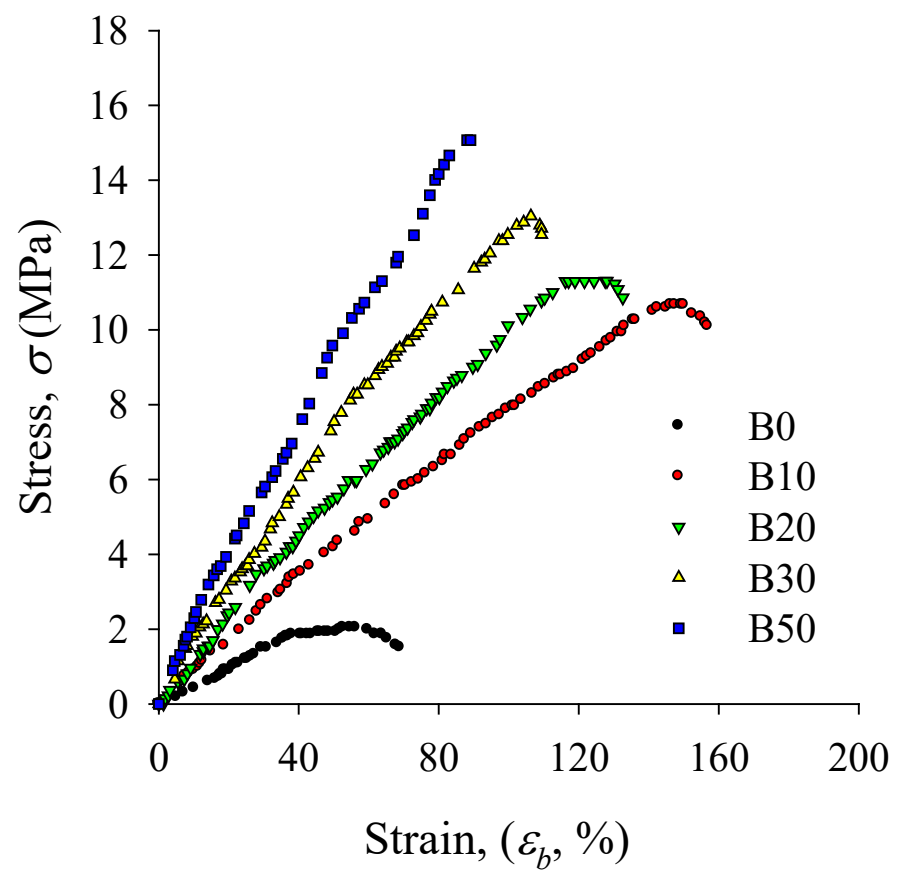

Fig. 1: Stress-strain curves of carbon black filled NR/IIR composites. 


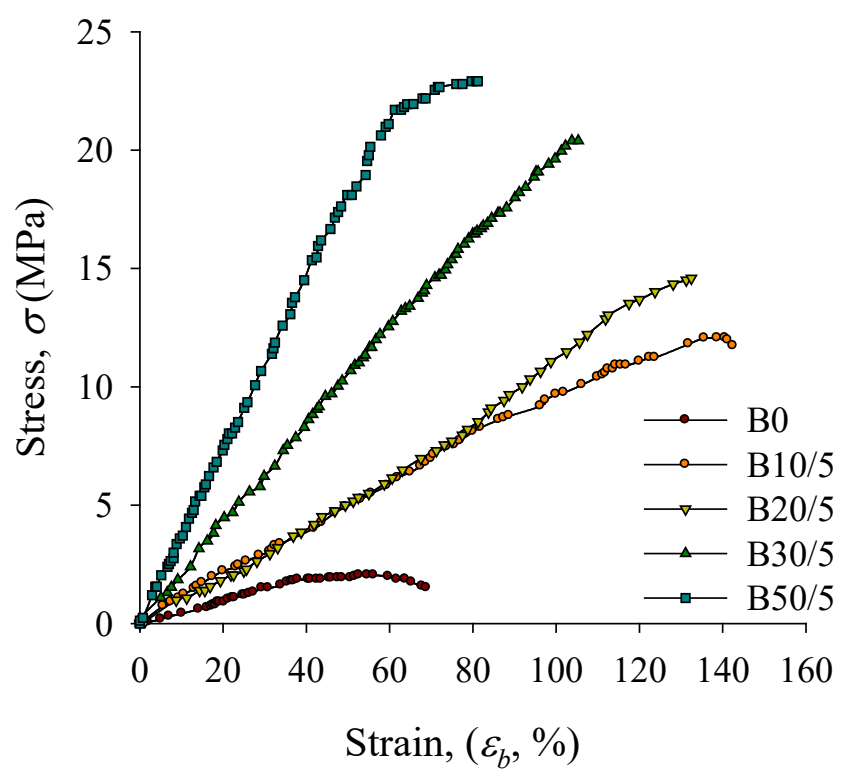

Fig. 2: Stress-strain curves of TCNP filled carbon black/ rubber composites. 


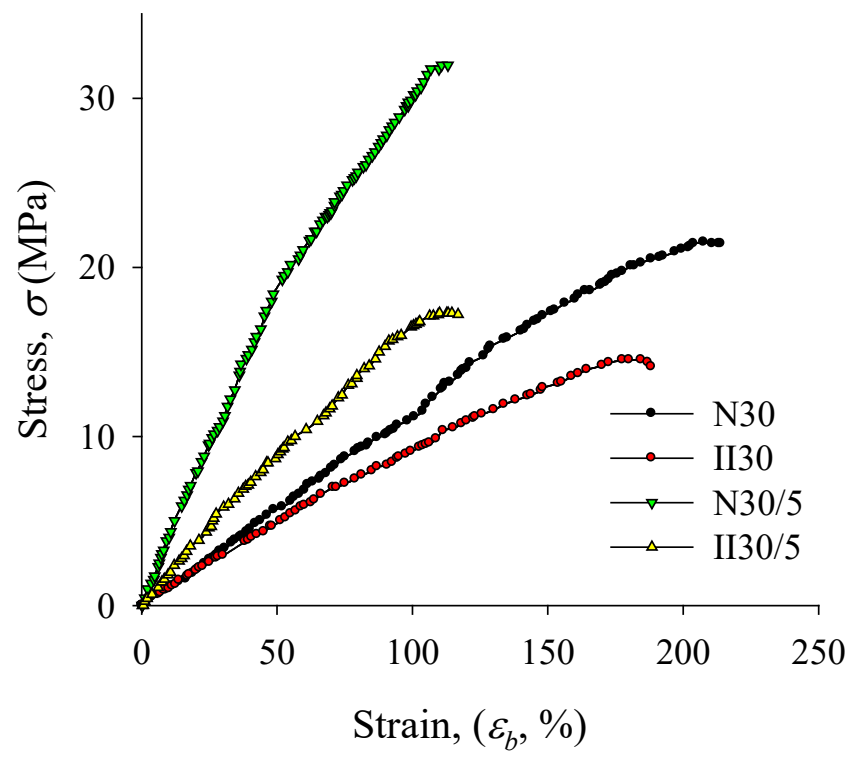

Fig. 3: Stress-strain curves of different rubber containing various fillers. 


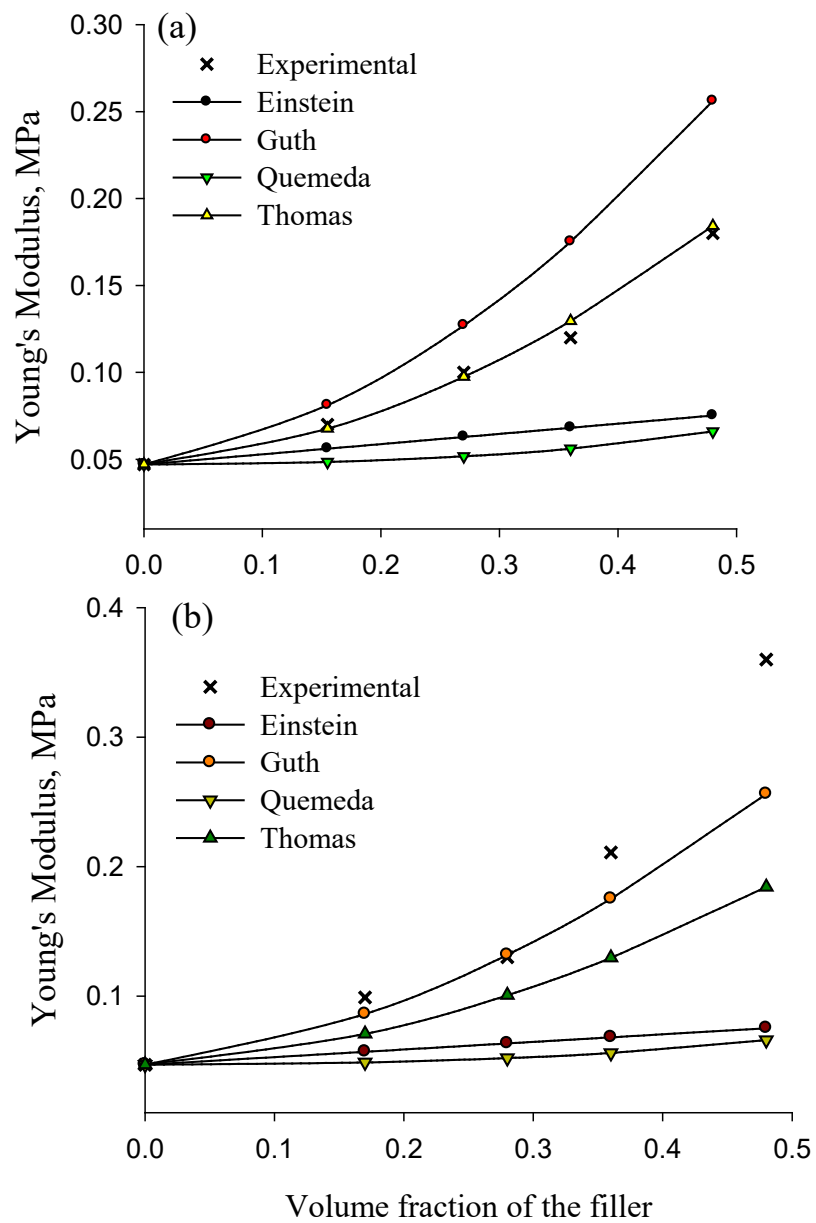

Fig. 4: Theoretical and Experimental Values of Young's modulus of CB loaded NR/IIR blends; (b) effect of TCNP loading. 

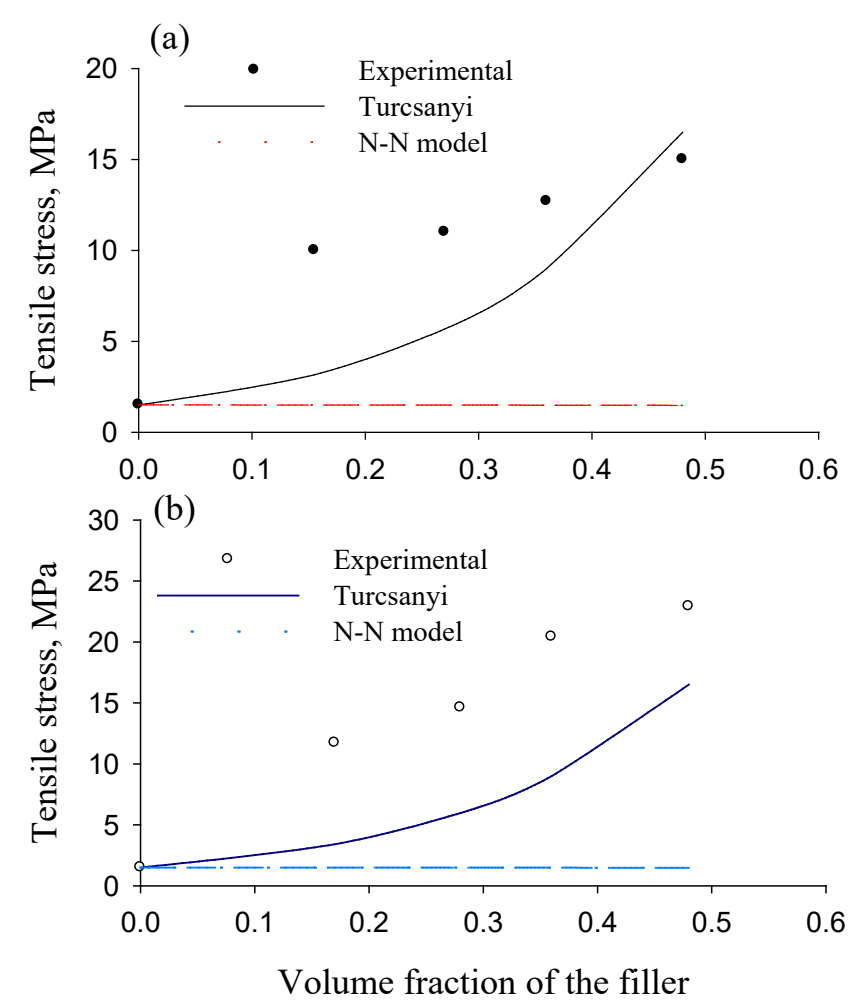

Fig. 5: Theoretical and Experimental Values of tensile strength of CB loaded NR/IIR blends; (b) effect of TCNP loading.

1. Ghobashy, M.M., Combined ultrasonic and gamma-irradiation to prepareTiO2@PET-g-PAAc fabric composite for self-cleaning application. Ultrasonics sonochemistry, 2017. 37: p. 529-535.

2. Ghobashy, M.M. and M.A. Elhady, $\mathrm{pH}$-sensitive wax emulsion copolymerization with acrylamide hydrogel using gamma irradiation for dye removal. Radiation Physics and Chemistry, 2017. 134: p. 47-55.

3. Ghobashy, M.M., et al., Controlling radiation degradation of a CMC solution to optimize the swelling of acrylic acid hydrogel as water and fertilizer carriers. Polymers for Advanced Technologies, 2021. 32(2): p. 514-524.

4. Ghobashy, M.M., et al., Characterization of Starch-based three components of gamma-ray crosslinked hydrogels to be used as a soil conditioner. Materials Science and Engineering: B, 2020. 260: p. 114645.

5. Ghobashy, M.M., I.M. Mousaa, and G.S. El-Sayyad, Radiation synthesis of urea/hydrogel core shells coated with three different natural oils via a layer-by-layer approach: An investigation of their slow release and effects on plant growth-promoting rhizobacteria. Progress in Organic Coatings, 2021. 151: p. 106022. 
Figures

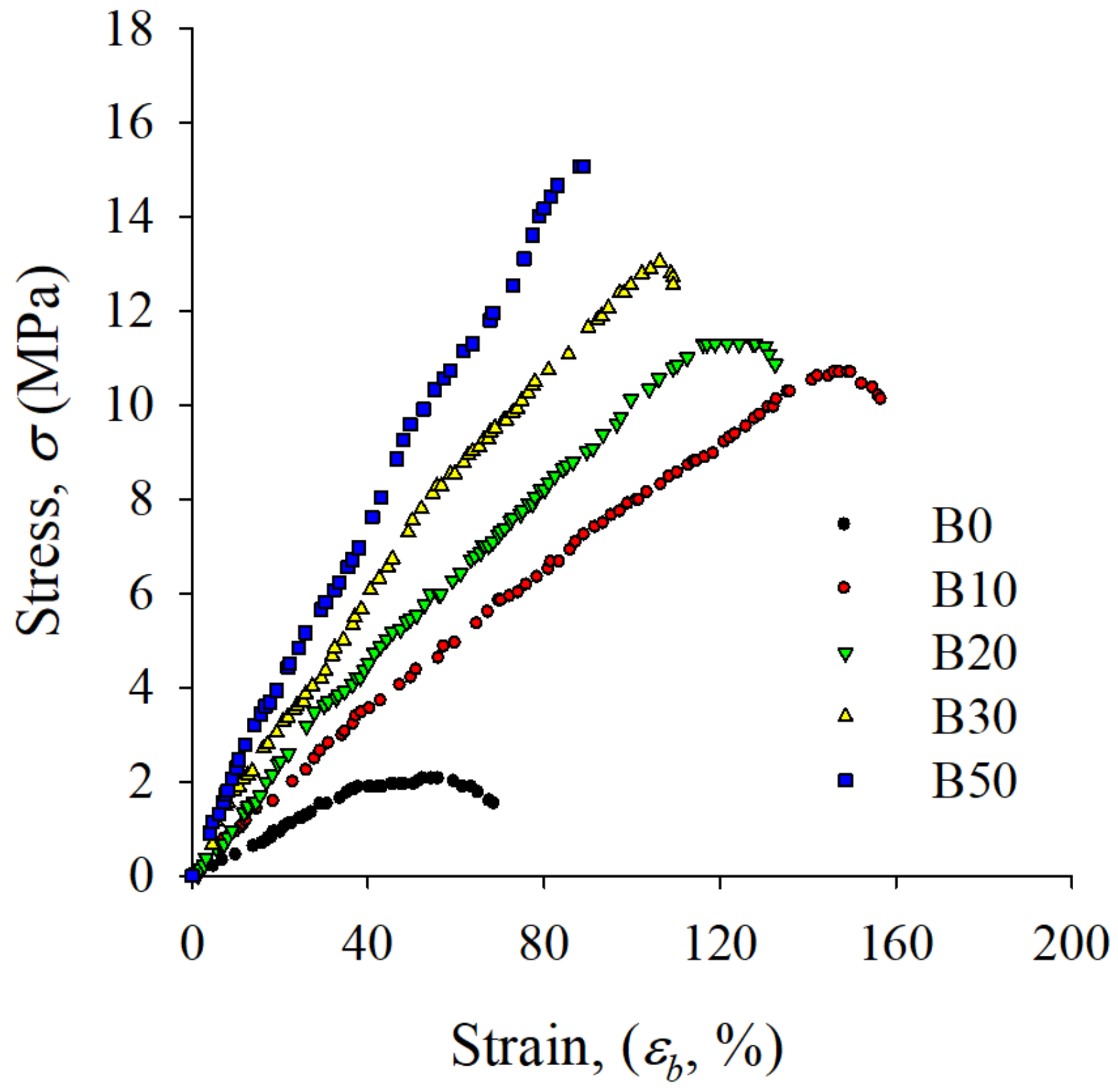

Figure 1

Stress-strain curves of carbon black filled NR/IIR composites. 


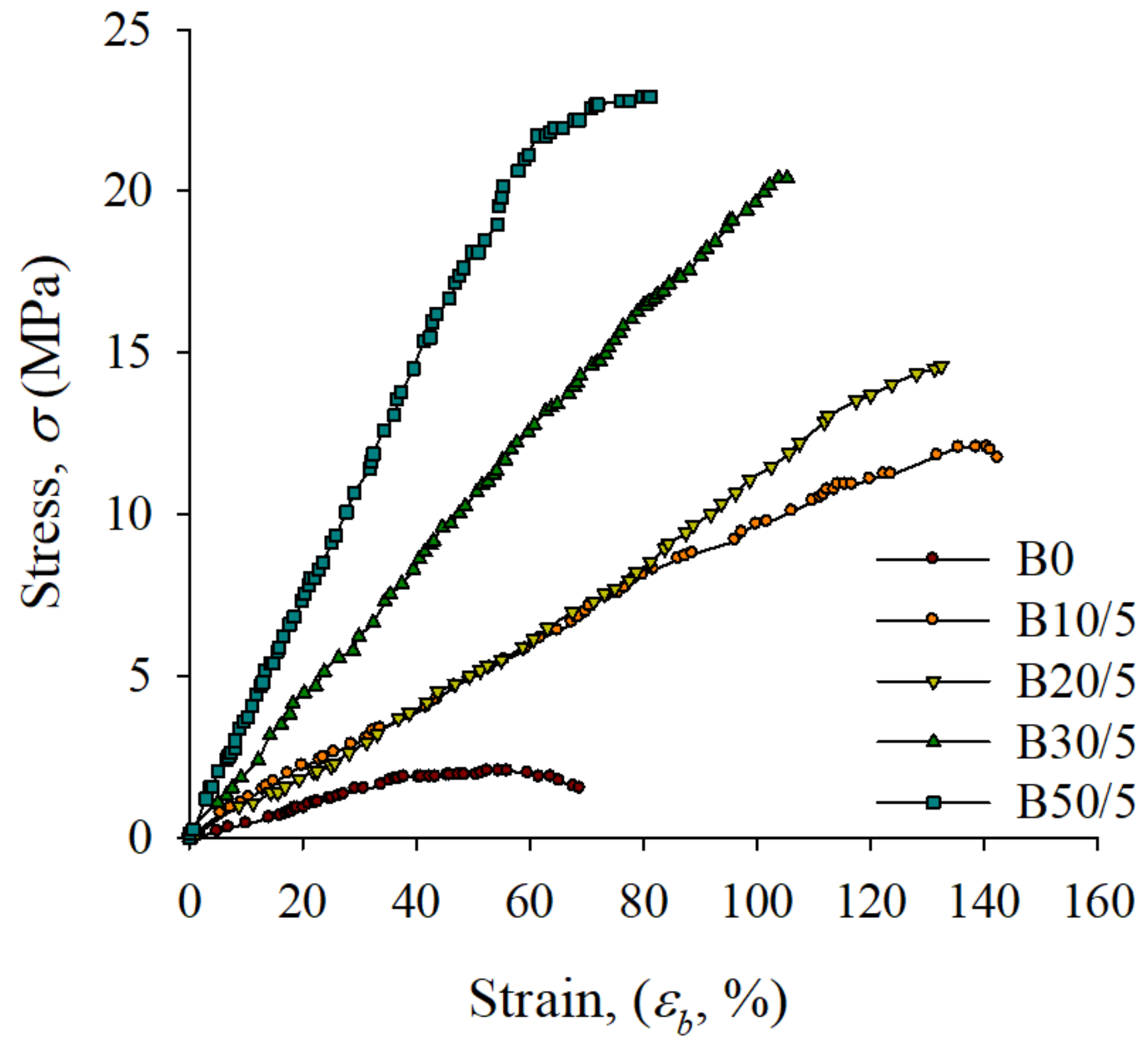

Figure 2

Stress-strain curves of TCNP filled carbon black/ rubber composites. 


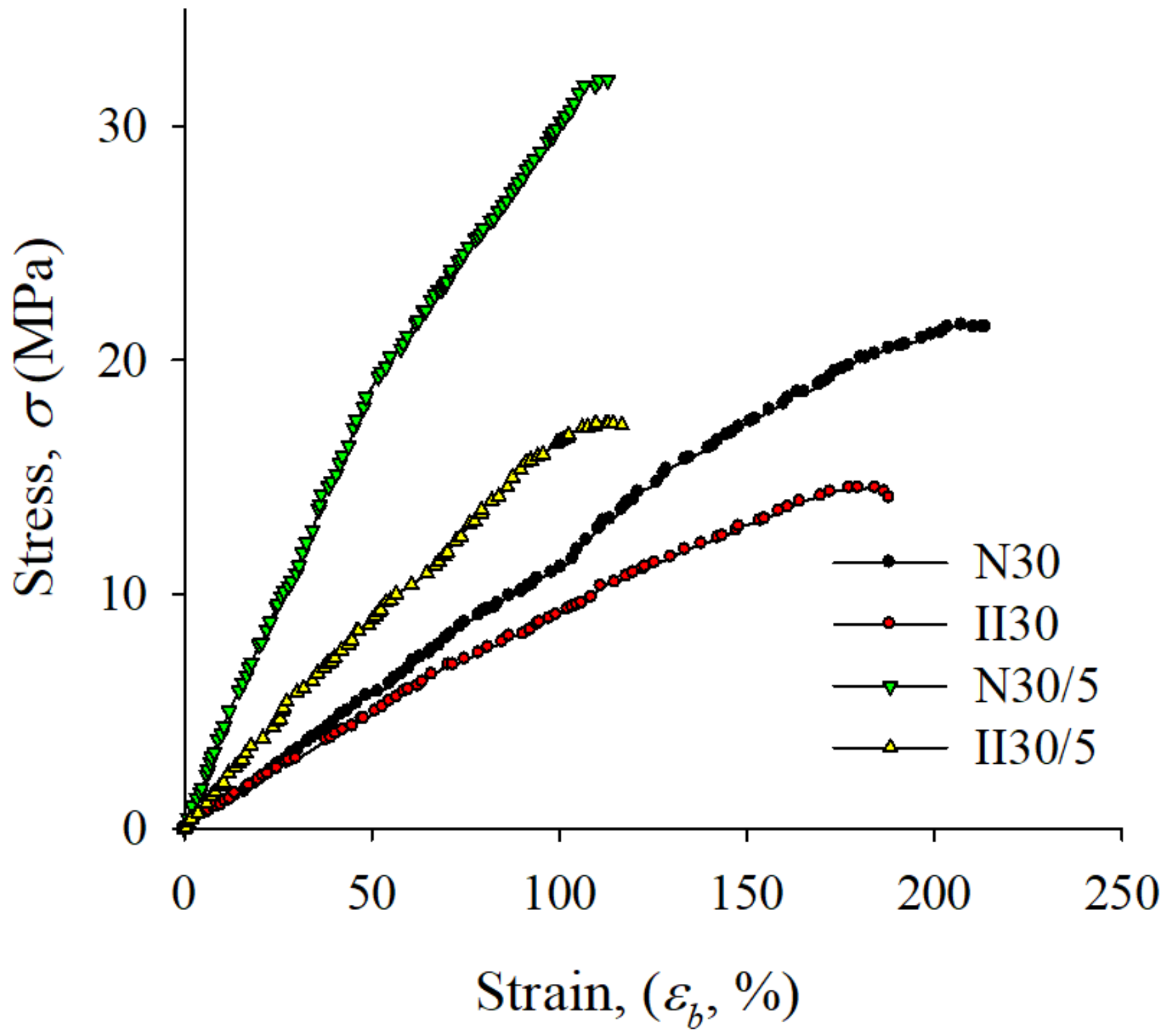

Figure 3

Stress-strain curves of different rubber containing various fillers. 

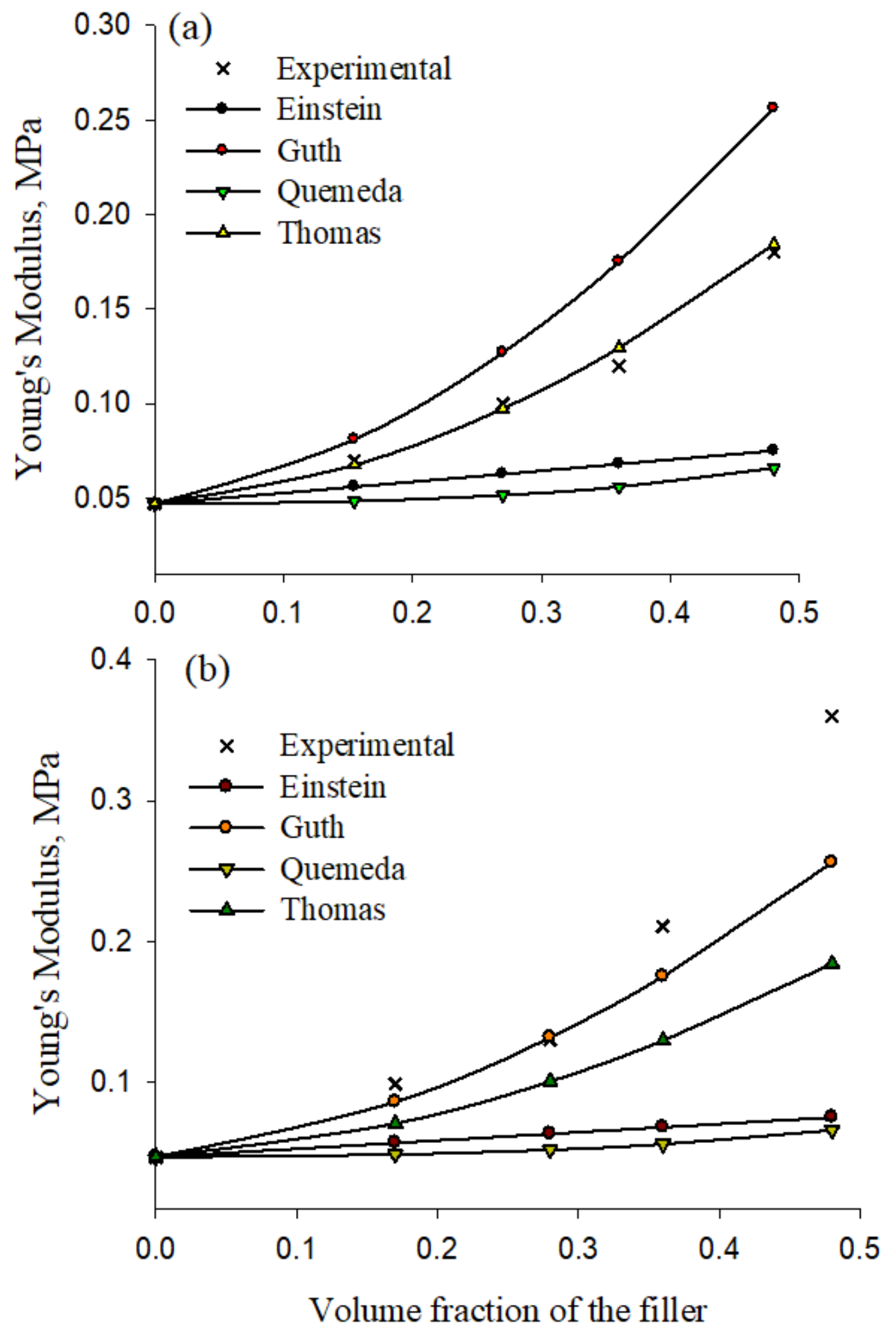

Figure 4

Theoretical and Experimental Values of Young's modulus of CB loaded NR/IIR blends; (b) effect of TCNP loading. 

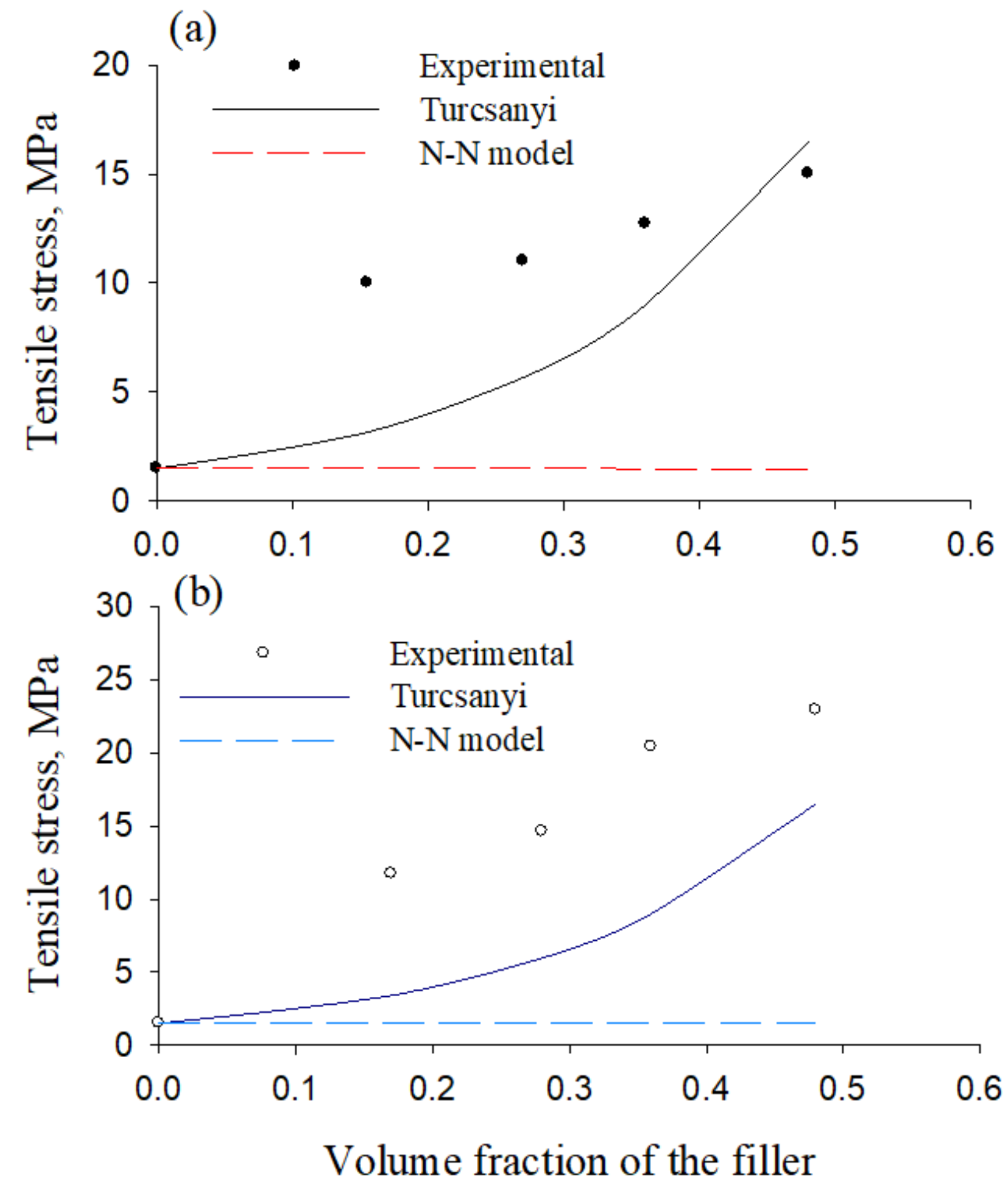

Figure 5

Theoretical and Experimental Values of tensile strength of CB loaded NR/IIR blends; (b) effect of TCNP loading. 